\title{
Preliminary data suggestive of a novel translational approach to mesothelioma treatment: imatinib mesylate with gemcitabine or pemetrexed
}

\author{
Pietro Bertino, Camillo Porta, Dario Barbone, Serena Germano, Sara Busacca, Sabrina Pinato, \\ Giancarlo Tassi, Roberto Favoni, Giovanni Gaudino, Luciano Mutti
}

See end of article for

authors' affiliations

Thorax 2007;62:690-695. doi: 10.1136/thx.2006.069872

Correspondence to: Dr Giovanni Gaudino, DISCAFF Department and DFBC Center, University of Piemonte Orientale "A Avogadro", 28100 Novara, Italy; giovanni. gaudino@unipmn.it

Received 3 August 2006 Accepted 19 January 2007 Published Online First 22 February 2007
Background: Malignant mesothelioma is a cancer which is refractory to current treatments. Imatinib mesylate is a selective inhibitor of tyrosine kinases such as bcr-abl, c-Kit, c-Fms and platelet derived growth factor receptor $\beta$ (PDGFR $\beta$ ). PDGFR $\beta$ is often overexpressed in mesothelioma cells and is a therapeutic target for imatinib in some solid tumours. A study was undertaken to assess whether imatinib alone or combined with chemotherapeutic agents may be effective for treating mesothelioma.

Methods: Cultures from mesothelioma MMP, REN and ISTMES2 cell lines were treated with imatinib alone or in combination with a chemotherapeutic agent.

Results: Imatinib induced cytotoxicity and apoptosis selectively on PDGFR $\beta$ positive mesothelioma cells via blockade of receptor phosphorylation and interference with the Akt pathway. Of the chemotherapeutic agents tested in combination with imatinib, a synergistic effect was obtained with gemcitabine and pemetrexed.

Conclusions: This study provides a rationale for a novel translational approach to the treatment of mesothelioma which relies on enhancement of tumour chemosensitivity by inhibition of Akt.
M alignant mesothelioma (MMe) is an asbestos-related tumour, the incidence of which is expected to rise dramatically in Europe. ${ }^{1}$ In the USA the incidence of MMe has already increased by $90 \%$ in the last few years. ${ }^{2}$ Because of its biological aggressiveness, MMe is nearly always fatal except in rare less advanced cases, with a median survival of 12.6 months. ${ }^{3}$

A number of growth factors such as hepatocyte growth factor (HGF), ${ }^{45}$ vascular endothelial growth factor $(\mathrm{VEGF})^{67}$ and insulin-like growth factor- 1 and $-2^{8}$ have been shown to play a significant role in the development and progression of MMe. Moreover, several studies have reported a crucial role for platelet derived growth factor (PDGF) A and B in MMe cell growth. ${ }^{9}$ A high level of expression of PDGF receptor $\beta$ (PDGFR $\beta$ ) was seen in MMe cells but not in normal human mesothelial cells (HMC), mostly expressing PDGFR $\alpha{ }^{10}$ Furthermore, increased expression of PDGF A and B was detected at higher levels in MMe cells than in HMC, ${ }^{11}$ and a significant reduction in MMe cell growth or migration was observed by blocking PDGF A and B. ${ }^{12}$ Expression of c-Kit on MMe cells has been demonstrated by some authors, although its role in this tumour is controversial. ${ }^{13-15}$ Production of macrophage colony stimulating factor (M-CSF) by mesothelial cells has already been reported, ${ }^{16}$ and inhibition of C-Fms receptor by imatinib has been demonstrated. ${ }^{17}$

Many cytokines are released in the microenvironment by tumour stromal cells, and PDGF paracrine stimulation has been demonstrated in human tumours, particularly MMe. ${ }^{18} 19$ PDGFR $\beta$ activated by PDGF B can induce PI3K/Akt signalling ${ }^{20}$ which seems to be crucial for the survival of MMe cells. ${ }^{21}$

Imatinib is a selective inhibitor for a subset of tyrosine kinases including bcr-abl, c-Kit, PDGFR $\beta^{22}$ and c-Fms. ${ }^{17}$ PDGF receptors are expressed by several tumour cells and have been identified as potential therapeutic targets for imatinib. ${ }^{23}$ In mesothelioma the extent of PDGFR $\beta$ positive specimens ranges from about $30 \%$ to $45 \%$ in different studies. ${ }^{24} 25$ Although the therapeutic inefficacy of imatinib monotherapy for mesothelioma has recently been reported, ${ }^{25}{ }^{26}$ combination therapies with imatinib in mice yielded successful results. ${ }^{27} 28$ Gemcitabine, cisplatin, etoposide, doxorubicin and, more recently, pemetrexed have been shown to be active in the treatment of MMe. Combined treatment with cisplatin/pemetrexed and cisplatin/gemcitabine have been found to be more effective than each single agent used alone. ${ }^{29}$ The aim of the present study is to investigate a translational approach which assesses the possible efficacy of imatinib as a single agent and in combination treatment for MMe.

\section{METHODS}

\section{Cell cultures}

Mesothelioma cells were derived from pleural effusions and stabilised in culture as continuous cell lines. MMP cells and primary HMC were characterised and cultured as previously described. ${ }^{5}$ REN cells were kindly provided by Dr Albelda and ISTMES2 were from the IST cell depository of Genoa (Italy).

\section{Drugs}

Imatinib was kindly provided by Novartis (Basel, Switzerland), and gemcitabine and pemetrexed were provided by Lilly (Indianapolis, Indiana, USA). Commercially available cisplatin, doxorubicin and etoposide were obtained from Alexis (Lausen, Switzerland).

\section{Signal transduction}

Cells were grown in $0.2 \%$ fetal bovine serum (FBS) for $24 \mathrm{~h}$, then pre-incubated for $90 \mathrm{~min}$ in the presence or absence of $10 \mu \mathrm{M}$ imatinib. Purified PDGF (R\&D, Milan, Italy), $20 \mathrm{ng} / \mathrm{ml}$, was added to the same medium. Immunoprecipitation and

Abbreviations: HGF, hepatocyte growth factor; HMC, human mesothelial cells; $L_{50}$, lethal concentration killing $50 \%$ of cells; $M-C S F$, macrophage colony stimulating factor; $M M e$, malignant mesothelioma; PDGF, platelet derived growth factor; PDGFR $\beta$, PDGF receptor $\beta$; VEGF, vascular endothelial growth factor 
immunoblotting were performed as previously described. ${ }^{5}$ Antibodies used were: PDGFR $\beta$, phospho-PDGFR $\beta$, c-Kit, cFms (Santa Cruz Biotechnology, USA), phospho-Akt-Ser473 (Cell Signaling, USA), phosphotyrosine (UBI, USA) and phospho-Erkl/2 (Sigma, USA). Reactions were detected by the Enhanced Chemiluminescence System (ECL, Amersham, UK).

\section{Cytotoxicity and apoptosis}

Subconfluent cells in 96-well plates were exposed for $48 \mathrm{~h}$ to medium supplemented with $2 \%$ FBS, with or without different drugs at concentrations ranging from $1 \times 10^{-10} \mathrm{M}$ to $1 \times 10^{-3} \mathrm{M}$. Cell viability was assessed by MTT assay ${ }^{30}$ on eight replicas at each concentration point to determine single drug lethal concentration $\left(\mathrm{LC}_{50}\right)$ values. Normalised cytotoxicity percentages were obtained from the formula: $\left(A_{570}\right.$ mean values of extracts from treated samples/ $A_{570}$ mean values of extracts from untreated control samples) $\times 100$.

LC $_{50}$ values, calculated using Origin software (Microcal Software, USA), were used to draw the theoretical addictivity isobole according to the $50 \%$ isobologram method. ${ }^{31}$ A series of dose-response curves were then generated for each chemotherapeutic drug as above in the presence of several fixed concentrations of imatinib. The resulting $\mathrm{LC}_{50}$ values were plotted on the isobologram for assessment of the hypothetical superadditive effect.

Apoptosis was evaluated by TUNEL analysis (DeadEnd Colorimetric TUNEL System, Promega, USA) following treatment with imatinib, alone or combined with gemcitabine or pemetrexed, and the specific $\mathrm{LC}_{50}$ values were determined by MTT analysis in each cell type as follows. MMP: imatinib $3 \times 10^{-7} \mathrm{M}$, gemcitabine $5 \times 10^{-7} \mathrm{M}$, pemetrexed $6.5 \times 10^{-6} \mathrm{M}$; REN: imatinib $1 \times 10^{-6} \mathrm{M}$, gemcitabine $5 \times 10^{-9} \mathrm{M}$, pemetrexed $1 \times 10^{-5} \mathrm{M}$; ISTMES2: imatinib $4 \times 10^{-6} \mathrm{M}$, gemcitabine $1 \times 10^{-9} \mathrm{M}$, pemetrexed $5 \times 10^{-6} \mathrm{M}$. In brief, subconfluent cells plated on glass slide flaskets (NUNC, Rochester, NY, USA) were exposed to medium supplemented with $2 \%$ FBS containing the different drugs for $48 \mathrm{~h}$ and subsequently fixed in $10 \%$ formalin. Biotin-dU positive nuclei were counted on 10 fields with at least 100 cells in the same slide. Values are expressed as the mean $( \pm S E)$ percentage of positive nuclei of the total counted.

\section{Statistical analysis}

For the cytotoxicity assay we performed three separate experiments for each drug and drug combination in the different cell types. Data from each experiment are expressed as mean (SE) values of eight determinations for every concentration point. All mean values from each of the three experiments were used to calculate the curve with the best fit using the Origin software and to calculate the corresponding $\mathrm{LC}_{50}$ value with confidence limits by regression analysis. These $\mathrm{LC}_{50}$ values were compared using the Student's $t$ test with theoretically additive doses and their confidence intervals were calculated as described by Tallarida. ${ }^{32}$

For apoptosis, statistical differences between the theoretical additive effects of the chemotherapeutic agents (gemcitabine or pemetrexed) plus imatinib vs the measured effects of imatinib/ chemotherapeutic combinations were evaluated by the Student's $t$ test.

In all statistical evaluations the significance threshold is specified in the text.

\section{RESULTS}

Expression of PDGFRß, c-Kit and c-Fms by MMe cells

We evaluated the expression of PDGFR $\beta$, c-Kit (tyrosine kinase receptor for stem cell factor) and c-Fms (M-CSF receptor) by immunoprecipitation and immunoblotting analysis on a panel of eight MMe cell lines. Five of the eight cell lines were positive for PDGFR $\beta$ (see fig 1 in supplementary data file available online at http://thorax.bmj.com/supplemental). Of the PDGF receptors, only PDGFR $\beta$ (but not PDGFR $\alpha$ ) was expressed in MMe cells examined. We selected three MMe cell lines for their different representative expression pattern. PDGFR $\beta$ was expressed at a higher level in MMP and REN cells than in ISTMES2 cells, while untransformed HMC did not express the PDGFR $\beta$ receptor. The expression of c-Kit and c-Fms occurred at higher levels in MMP cells and was reduced in REN and ISTMES2 cells. HMC only displayed a very low level of c-Fms expression (fig lA).

\section{Effect of imatinib-mediated PDGFR $\beta$ inhibition on Akt}

MMe cells positive for PDGFR $\beta$ were also tested by immunoprecipitation with PDGFR $\beta$ antibodies followed by immunoblotting with phosphotyrosine antibodies after growing cells in low serum conditions. MMe cells displayed negligible levels of tyrosine phosphorylation whereas the addition of recombinant PDGF B increased the receptor phosphorylation of all cells (fig 1B, upper panel). Neither c-Kit nor c-Fms phosphorylation was detectable in the MMe cells (data not shown).

We then determined whether treatment with imatinib could interfere with signalling pathways elicited by this receptor. In low serum conditions, only MMP cells displayed autonomous Akt activity (determined as Ser ${ }^{473}$ phosphorylation) whereas, on stimulation with PDGF, tyrosine phosphorylation of PDGFR $\beta$ and Akt phosphorylation were increased but were markedly inhibited by $10 \mu \mathrm{M}$ imatinib in all MMe cells examined. Basal Erkl/2 activity was slightly enhanced after PDGF in MMP and, to a lesser extent, in REN cells, while both activities were barely affected by treatment with imatinib $10 \mu \mathrm{M}$ (fig 1B, lower panel).

Conversely, Akt inhibition was complete and comparable to that obtained by treatment with the phosphatidylinositol-3 kinase (PI3K) inhibitor wortmannin at a concentration of $100 \mathrm{nM}$ (fig 1C). Interestingly, Akt activity in MMP cells, expressing also HGFR/Met, ${ }^{5}$ was increased by the addition of recombinant HGF ( $100 \mathrm{ng} / \mathrm{ml}$ ) but was not affected by imatinib (fig 1D). This indicates a selective blockade of PDGFR $\beta$ dependent Akt signalling by imatinib.

\section{Effect of imatinib on viability of MMe cells expressing PDGFR $\beta$}

In view of the crucial role played by Akt in determining survival of HMC and MMe cells, ${ }^{21}$ we postulated that imatinib could negatively affect the viability of PDGFR $\beta$-positive MMe cells. After incubation for $48 \mathrm{~h}$ with up to $100 \mu \mathrm{M}$ imatinib, cell viability tested by the MTT assay was markedly decreased with

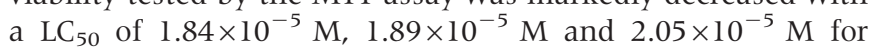
MMP, REN and ISTMES2 cells, respectively. Gemcitabine and pemetrexed have already been shown to be particularly effective in combination with cisplatin for MMe chemotherapy. ${ }^{29}$ We therefore tested the cytotoxic effect induced by these two agents in the presence of different concentrations of imatinib. As expected, gemcitabine and pemetrexed killed MMe cells in a dose-dependent manner. The presence of imatinib modified the profile of the dose-response curves with a shift towards lower $\mathrm{LC}_{50}$ values and a decrease in the fraction of drug-resistant cells (fig 2A).

We did not observe any evidence of PDGFR $\beta$ phosphorylation/activation by either gemcitabine or pemetrexed (see fig 2 in supplementary data file available online at http://thorax.bmj. com/supplemental), as recently reported for epidermal growth factor receptor. ${ }^{33}$ 



Figure 1 Expression of platelet derived growth factor receptor $\beta$ (PDGFR $\beta$ ) in malignant mesothelioma (MMe) cells. (A) Immunoblotting with PDGFR $\beta$, c-Kit and c-Fms antibodies on human mesothelial cells (HMC) and three representative $M M e$ cell lines. Controls: human dermal fibroblasts (HDF) expressing PDGFR $\beta$ and CCRF, CCRF-HSB-2, human leukaemic lymphoblast cells expressing c-Kit and c-Fms. (B) Immunoprecipitation with PDGFR $\beta$ antibodies followed by immunoblotting with phosphotyrosine antibodies (upper panel); immunoblotting with the indicated antibodies on whole lysates (lower panel). In both panels MMP, REN and ISTMES2 cells were in low serum (-) or stimulated with PDGF in the presence or absence of $10 \mu \mathrm{M}$ imatinib or (C) $100 \mathrm{nM}$ wortmannin. (D) Immunoblotting with PAkt (P-Ser 473) antibodies of MMP cells stimulated by $50 \mathrm{ng} / \mathrm{ml}$ hepatocyte growth factor (HGF) in the presence or absence of $10 \mu \mathrm{M}$ imatinib.

\section{Synergy of imatinib with gemcitabine and pemetrexed in inducing $M M e$ cell death}

Activation of tyrosine kinase receptors by ligands induces PI3K and Akt activities, exerting several biological effects including increased cell survival with relevant effects on human carcinogenesis. ${ }^{34}$ We have recently shown that Akt plays a major survival role for MMe cells. ${ }^{21}$ Therefore, based on the clear-cut toxic effect induced by imatinib on MMe cells mediated by the inhibition of the PI3K/Akt pathway, we hypothesised that this inhibitor may also reinforce cytotoxicity generated by other cytotoxic agents.

Combined treatments of imatinib with other chemotherapeutic drugs were therefore analysed by the isobologram plot method. ${ }^{31}$ Interestingly, only imatinib/gemcitabine and imatinib/pemetrexed combinations showed a significant synergism in reducing MMP $(p \leqslant 0.001)$ and REN (ranging from $p \leqslant 0.01$ to $p \leqslant 0.001$ ) cell viability compared with the effects observed with single agents alone. This was revealed by inserting all $\mathrm{LC}_{50}$ values on a concave upward curve below the isoeffective plot (fig 2B). In REN cells the synergistic effect is still appreciable, although to a lower extent, while in ISTMES2 cells the effect of imatinib in combination with other chemotherapeutic agents was significantly antagonistic (ranging from $p \leqslant 0.05$ to $\mathrm{p} \leqslant 0.001)$.

The effectiveness of these combined treatments was confirmed when cell death was investigated by TUNEL analysis. The combination of imatinib with gemcitabine or pemetrexed induced a significant increase in apoptosis $(p \leqslant 0.001)$ compared with the theoretical additive effect of each chemotherapeutic agent with imatinib (table 1). No synergistic effect was observed with any of the other chemotherapeutic drugs (results not shown). Interestingly, the concentrations of the single agents used in the combined treatment were much lower than those obtained at therapeutic dosages.

\section{DISCUSSION}

We describe here some preclinical results which provide a rationale for a novel combined approach to MMe treatment via inhibition of PDGFR $\beta$ signalling. Our findings on cultured cells are in accordance with previous evidence of PDGFR $\beta$ expression in MMe cells and a lack of expression in normal HMC. ${ }^{10}$ With regard to the relevance of PDGFR $\beta$ expression in vivo, the percentage of positive specimens reported is in the range of 30$45 \%$ in the different studies reported. ${ }^{24}{ }^{25}$ These data therefore offer a rationale for testing the tyrosine kinase inhibitor imatinib on PDGFR $\beta$ activity in MMe cells.

Autocrine or paracrine mechanisms may explain the activation of PDGFR $\beta$ in vivo. An autocrine loop has been described as an activating mechanism leading to tyrosine kinase receptor activity in MMe cells, ${ }^{5}$ and the stromal microenvironment has been shown to be a fundamental source of activating ligands for PDGFR in human tumours. ${ }^{35}$ Tyrosine phosphorylation of this receptor in MMP and REN cells is inhibited by imatinib, leading to cytotoxic effects and addressing the role of downstream PI3K/Akt survival signalling.

We and others have shown that Akt activation in MMe cells is a crucial signalling pathway which contributes to the MMe malignant phenotype. ${ }^{21}{ }^{36}$ Even though this is also dependent on the activity of several other tyrosine kinase receptors, our findings show that specific interference with the PDGFR $\beta$ dependent pathway causes an increase in cell chemosensitivity.

Preclinical studies on several human solid tumours have confirmed the efficacy of imatinib as a cytotoxic agent. ${ }^{37-40}$ In chronic myeloid leukaemia and gastrointestinal stromal tumour the carcinogenic role of the fusion protein BCR-ABL ${ }^{39}$

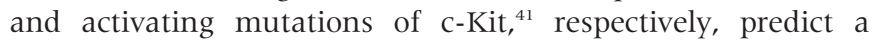
clinical response to imatinib. Conversely, in MMe, two recent negative reports gave clear evidence that imatinib monotherapy is ineffective. ${ }^{25}{ }^{26}$ On the other hand, combined treatment with imatinib and different chemotherapeutic agents has been shown to be effective in mice. ${ }^{27} 28$

Our results clearly indicate that PDGFR $\beta$ expression in MMe cells is essential for sensitivity to imatinib and for the synergy observed between imatinib and gemcitabine or pemetrexed. 

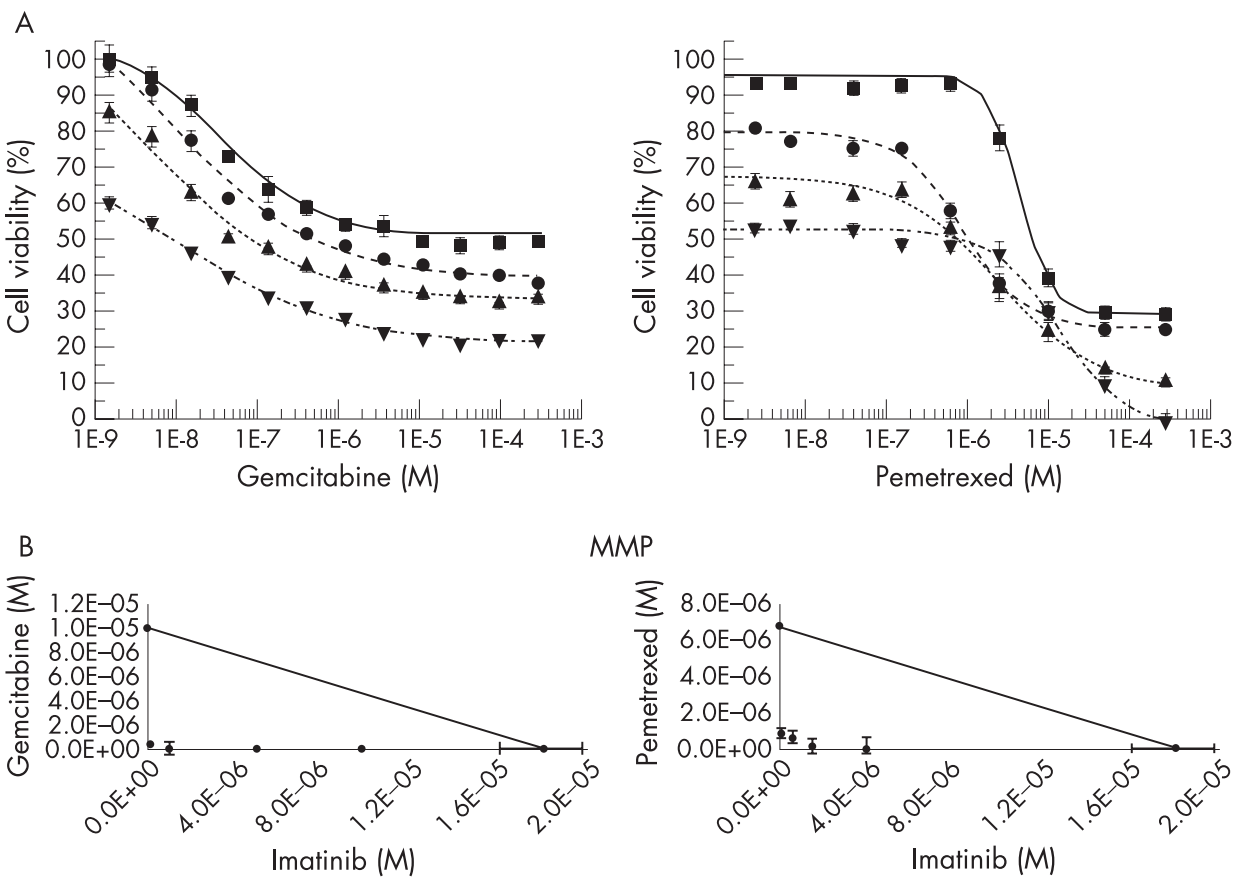

MMP

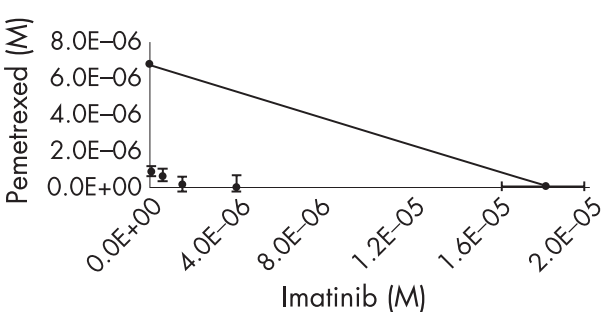

REN
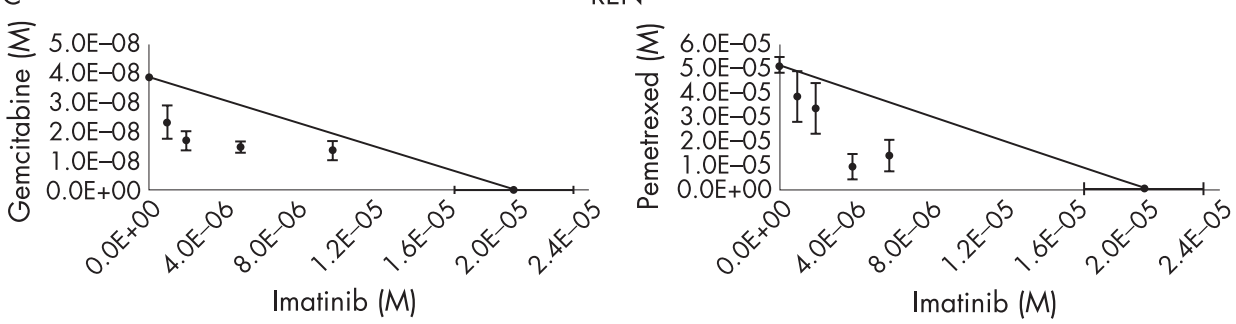

ISTMES2

D

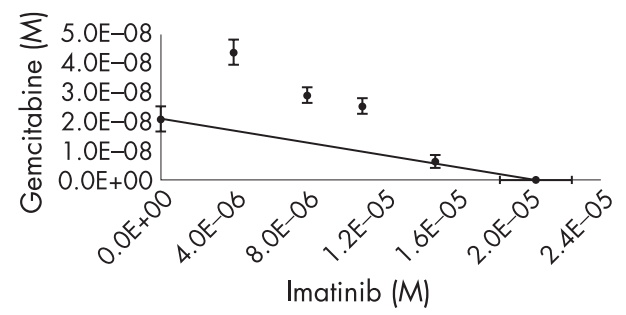

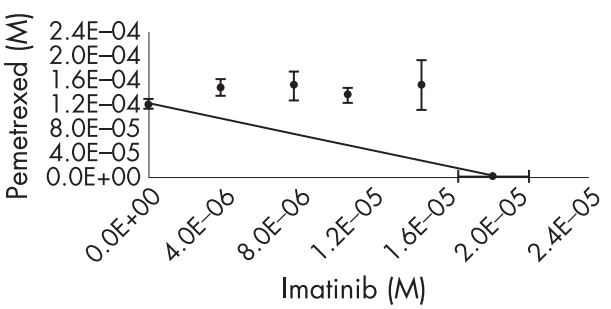

Figure 2 Synergy of imatinib with gemcitabine and pemetrexed. (A) Doseeffect curves of cell viability for gemcitabine (left) and pemetrexed (right) in the presence of different concentrations of imatinib. For the imatinib/gemcitabine combination: $\bullet$, $1 \times 10^{-7} \mathrm{M} ; \boldsymbol{\Lambda}, 2.5 \times 10^{-6} \mathrm{M} ; \boldsymbol{\nabla}$, $1 \times 10^{-4} \mathrm{M}$. For the imatinib/pemetrexed combination: $\bullet, 3 \times 10^{-7} \mathrm{M} ; \boldsymbol{\Lambda}, 6 \times 10^{-7} \mathrm{M}$ $\boldsymbol{\nabla}, 1.5 \times 10^{-6} \mathrm{M}$. Representative data from three experiments conducted with eight determinations for each point. Points represent mean $( \pm S E)$ percentage . (B-D)

$50 \%$ isobologram plot for imatinib in combination with gemcitabine (left) and pemetrexed (right) on MMP, REN and ISTMES2 cells. Points are mean ( \pm SE) $50 \%$ lethal concentration $\left(\mathrm{LC}_{50}\right)$ calculated by regression analysis.
However, when all three receptors sensitive to imatinib and upstream of the PI3K/Akt pathway are co-expressed in the same cell type, as in MMP, the synergistic effect is higher than in REN cells where only two of them are expressed (PDGFR $\beta$ and c-Kit).
Gemcitabine and pemetrexed are known to be active on MMe cells $^{42}$ and their combination with imatinib has intriguing implications. In particular, the synergism shown in this study indicates that very low doses of chemotherapeutic agents should be sufficient to exert a therapeutic effect.

Table 1 TUNEL analysis of apoptosis induced in malignant mesothelioma (MMe) cells by single drugs or by drug combinations

\begin{tabular}{llll}
\hline Treatment & MMP & REN & ISTMES2 \\
\hline Imatinib & $1.10(0.35)$ & $1.00(0.23)$ & $1.70(0.19)$ \\
Gemcitabine & $1.58(0.42)$ & $3.07(0.51)$ & $2.80(0.32)$ \\
Pemetrexed & $0.98(0.47)$ & $1.04(0.26)$ & $1.00(0.26)$ \\
Imatinib + gemcitabine & $5.34(0.40)^{*}$ & $9.72(0.48)^{*}$ & $1.02(0.48)^{*}$ \\
Imatinib + pemetrexed & $8.48(0.40)^{*}$ & $4.72(0.26)^{*}$ & $0.04(0.26)^{*}$ \\
\hline
\end{tabular}

Data are expressed as the mean (SE) percentage of biotin-dU positive nuclei for 100 counted cells at a magnification of $100 \times$. The values for each treatment were subtracted from untreated control values. Different concentrations of drugs were used, as described in the Methods section.

${ }^{*} p \leqslant 0.001$, difference between theoretical additive effects of chemotherapeutics (gemcitabine or pemetrexed) + imatinib vs measured effects of imatinib/chemotherapeutic combinations. 
Given our previous findings, ${ }^{21}$ the mechanism underlying the observed in vitro synergy is probably imatinib-dependent PDGFR $\beta$ inhibition which, in turn, leads to Akt inactivation resulting in sensitisation of MMe cells to low chemotherapeutic concentrations. However, it is conceivable that other biological effects could play a role in humans. Reduction of the intratumoral interstitial fluid pressure and increased uptake of chemotherapeutics by imatinib have been shown in vivo. ${ }^{27}$ In addition, imatinib has been shown to interfere with VEGF expression and associated neoangiogenesis. ${ }^{43}$

Although some progress has been made in the treatment of MMe, the results are still unsatisfactory and MMe remains an ideal field in which to test new therapeutic approaches. ${ }^{42}$ Our work on the synergy between imatinib and chemotherapeutic drugs active in MMe provides a strong rationale for a new approach to the treatment of this disease and will be evaluated further in early phase clinical trials.

\section{ACKNOWLEDGEMENTS}

The authors thank Dr Patrizia Morbini, Institute of Pathology, San Matteo University Hospital, Pavia, Italy and also Dr M Rinaldi for advice on statistical analysis.

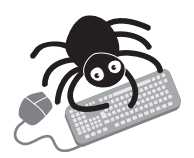

Further details are shown in figs 1 and 2 in the supplementary data file available online at $\mathrm{http}: / /$ thorax.bmj.com/supplemental.

\section{Authors' affiliations \\ Pietro Bertino, Dario Barbone, Serena Germano, Sara Busacca, Sabrina Pinato, Giovanni Gaudino, DISCAFF Department and DFB Center, University of Piemonte Orientale "A Avogadro", Novara, Italy \\ Camillo Porta, Medical Oncology, IRCCS San Matteo University Hospital, Pavia, Italy \\ Giancarlo Tassi, Chest Medicine Unit, Brescia Hospital, Brescia, Italy Roberto Favoni, National Cancer Institute, Genoa, Italy \\ Luciano Mutti, Local Health Unit, 11 Piemonte, Italy}

This work was supported by research grants to GG from AIRC (Associazione Italiana per la Ricerca sul Cancro), MARF (Mesothelioma Applied Research Foundation) and the Buzzi Foundation (Casale Monferrato, Italy). This work is part of G.I.Me. (Gruppo Italiano per lo Studio e la Terapia del Mesotelioma) network program.

Competing interests: None declared.

GG and LM contributed equally to the study.

\section{REFERENCES}

1 Peto J, Decarli A, La Vecchia C, et al. The European mesothelioma epidemic. Br J Cancer 1999;79:666-72.

2 Treasure T, Sedrakyan A. Pleural mesothelioma: little evidence, still time to do trials. Lancet 2004;364:1183-5.

3 Pass HI, Vogelzang N, Hahn S, et al. Malignant pleural mesothelioma. Curr Probl Cancer 2004;28:93-174.

4 Klominek J, Baskin B, Liu Z, et al. Hepatocyte growth factor/scatter factor stimulates chemotaxis and growth of malignant mesothelioma cells through c-met receptor. Int J Cancer 1998;76:240-9.

5 Cacciotti P, Libener R, Betta P, et al. SV40 replication in human mesothelial cells induces HGF/Met receptor activation: a model for viral-related carcinogenesis of human malignant mesothelioma. Proc Natl Acad Sci USA 2001;98:12032-7.

6 Strizzi L, Catalano A, Vianale G, et al. Vascular endothelial growth factor is an autocrine growth factor in human malignant mesothelioma. J Pathol 2001;193:468-75.

7 Cacciotti P, Strizzi L, Vianale G, et al. The presence of simian-virus 40 sequences in mesothelioma and mesothelial cells is associated with high levels of vascular endothelial growth factor. Am J Respir Cell Mol Biol 2002;26:189-93.

8 Hoang CD, Zhang $X$, Scott PD, et al. Selective activation of insulin receptor substrate- 1 and -2 in pleural mesothelioma cells: association with distinct malignant phenotypes. Cancer Res 2004;64:7479-85.

9 Garlepp MJ, Leong CC. Biological and immunological aspects of malignant mesothelioma. Eur Respir J 1995;8:643-50.
10 Langerak AW, van der Linden-van Beurden CA, Versnel MA. Regulation of differential expression of platelet-derived growth factor alpha- and beta-receptor mRNA in normal and malignant human mesothelial cell lines. Biochim Biophys Acta 1996;1305:63-70.

11 Pogrebniak HW, Lubensky IA, Pass HI. Differential expression of platelet derived growth factor-beta in malignant mesothelioma: a clue to future therapies? Surg Oncol 1993;2:235-40.

12 Klominek J, Baskin B, Hauzenberger D. Platelet-derived growth factor (PDGF) BB acts as a chemoattractant for human malignant mesothelioma cells via PDGF receptor beta-integrin alpha3betal interaction. Clin Exp Metastasis 1998; 16:529-39.

13 Horvai $\mathrm{AE}$, Li L, $\mathrm{X}_{\cup} \mathrm{Z}$, et al. c-Kit is not expressed in malignant mesothelioma. Mod Pathol 2003;16:818-22.

14 Butnor KJ, Burchette JL, Sporn TA, et al. The spectrum of Kit (CD117) immunoreactivity in lung and pleural tumors: a study of 96 cases using a singlesource antibody with a review of the literature. Arch Pathol Lab Med 2004; 128:538-43.

15 Catalano A, Rodilossi S, Rippo MR, et al. Induction of stem cell factor/c-Kit/slug signal transduction in multidrug-resistant malignant mesothelioma cells. J Biol Chem 2004;279:46706-14.

16 Lanfrancone L, Boraschi D, Ghiara P, et al. Human peritoneal mesothelial cells produce many cytokines (granulocyte colony-stimulating factor (CSF), granulocyte-monocyte-CSF, macrophage-CSF, interleukin-1 (IL-1), and IL-6) and are activated and stimulated to grow by IL-1. Blood 1992;80:2835-42.

17 Taylor JR, Brownlow N, Domin J, et al. FMS receptor for M-CSF (CSF-1) is sensitive to the kinase inhibitor imatinib and mutation of Asp-802 to Val confers resistance. Oncogene 2006;25:147-51.

18 Kindler HL. Moving beyond chemotherapy: novel cytostatic agents for malignant mesothelioma. Lung Cancer 2004;45(Suppl 1):S125-7.

19 Shih AH, Holland EC. Platelet-derived growth factor (PDGF) and glial tumorigenesis. Cancer Lett 2006;232:139-47.

20 Johnson MD, Okedli E, Woodard A, et al. Evidence for phosphatidylinositol 3kinase-Akt-p7S6K pathway activation and transduction of mitogenic signals by platelet-derived growth factor in meningioma cells. J Neurosurg 2002;97:668-75.

21 Cacciotti P, Barbone D, Porta C, et al. SV40-dependent AKT activity drives mesothelial cell transformation after asbestos exposure. Cancer Res 2005;65:5256-62.

22 George D. Platelet-derived growth factor receptors: a therapeutic target in solid tumors. Semin Oncol 2001;28(5 Suppl 17):27-33.

23 Abou-Jawde R, Choveiri T, Alemany C, et al. An overview of targeted treatments in cancer. Clin Ther 2003;25:2121-37.

24 Roberts F, Harper CM, Downie I, et al. Immunohistochemical analysis still has a limited role in the diagnosis of malignant mesothelioma. A study of thirteen antibodies. Am J Clin Pathol 2001;1 16:253-62.

25 Porta C, Mutti L, Tassi G. Negative results of an Italian Group for Mesothelioma (G.I.Me.) pilot study of single-agent imatinib mesylate in malignant pleural mesothelioma. Cancer Chemother Pharmacol 2007;59:149-50.

26 Mathy A, Baas P, Dalesio O, et al. Limited efficacy of imatinib mesylate in malignant mesothelioma: a phase II trial. Lung Cancer 2005;50:83-6.

27 Pietras K, Stumm M, Hubert M, et al. STI571 enhances the therapeutic index of epothilone B by a tumor-selective increase of drug uptake. Clin Cancer Res 2003;9:3779-87.

28 Yokoi K, Sasaki T, Bucana CD, et al. Simultaneous inhibition of EGFR, VEGFR, and platelet-derived growth factor receptor signaling combined with gemcitabine produces therapy of human pancreatic carcinoma and prolongs survival in an orthotopic nude mouse model. Cancer Res 2005;65:10371-80.

29 Tomek S, Manegold C. Chemotherapy for malignant pleural mesothelioma: past results and recent developments. Lung Cancer 2004;45(Suppl 1): S103-19.

30 Mosmann T. Rapid colorimetric assay for cellular growth and survival: application to proliferation and cytotoxicity assays. J Immunol Methods 1983;65:55-63.

31 Tallarida RJ. Drug synergism: its detection and applications. J Pharmacol Exp Ther $2001 ; 298: 865-72$.

32 Tallarida RJ. Statistical analysis of drug combinations for synergism. Pain 1992;49:93-7.

33 Feng FY, Varambally S, Tomlins SA, et al. Role of epidermal growth factor receptor degradation in gemcitabine-mediated cytotoxicity. Oncogene 2007;17:3431-9

34 Stein RC. Prospects for phosphoinositide 3-kinase inhibition as a cancer treatment. Endocr Relat Cancer 2001;8:237-48.

35 Sawyers C. Targeted cancer therapy. Nature 2004;432:294-7.

36 Rascoe PA, Cao X, Daniel JC, et al. Receptor tyrosine kinase and phosphoinositide-3 kinase signaling in malignant mesothelioma. J Thorac Cardiovasc Surg 2005; 130:393-400.

37 Krystal GW, Honsawek S, Litz J, et al. The selective tyrosine kinase inhibitor STI571 inhibits small cell lung cancer growth. Clin Cancer Res 2000;6:3319-26

38 Wang WL, Healy ME, Sattler M, et al. Growth inhibition and modulation of kinase pathways of small cell lung cancer cell lines by the novel tyrosine kinase inhibitor STI 571. Oncogene 2000;19:3521-8.

39 Druker BJ, Sawyers CL, Kantarjian H, et al. Activity of a specific inhibitor of the $\mathrm{BCR}-\mathrm{ABL}$ tyrosine kinase in the blast crisis of chronic myeloid leukemia and acute lymphoblastic leukemia with the Philadelphia chromosome. N Engl J Med 2001;344:1038-42.

40 Gonzalez I, Andreu EJ, Panizo A, et al. Imatinib inhibits proliferation of Ewing tumor cells mediated by the stem cell factor/KIT receptor pathway, and sensitizes 
cells to vincristine and doxorubicin-induced apoptosis. Clin Cancer Res 2004; 10:751-61.

41 Heinrich MC, Corless CL, Demetri GD, et al. Kinase mutations and imatinib response in patients with metastatic gastrointestinal stromal tumor. J Clin Oncol 2003;21:4342-9.
42 Vogelzang NJ, Porta C, Mutti L. New agents in the management of advanced mesothelioma. Semin Oncol 2005;32:336-50.

43 Beppu K, Jaboine J, Merchant MS, et al. Effect of imatinib mesylate on neuroblastoma tumorigenesis and vascular endothelial growth factor expression. J Natl Cancer Inst 2004;96:46-55.

\section{PULMONARY PUZZLE}

\section{Answer}

Transthoracic needle aspiration of the mass showed abundant small mature lymphocytes and some atypical cells with cytological abnormalities. An immunoperoxidase panel revealed a positive reaction with pankeratin, vimentin and LCA stains. Stains for MOC-31, Ber-EP4, TTF-1 and calretinin were negative. The pathologist at the local hospital suggested a possible large cell carcinoma of a lymphoepithelioma type but requested further investigation.

A CT-guided core biopsy stained for cytokeratin 5/6 and p63, supporting the diagnosis of a pleural-based thymoma. There was a separate infiltrate consistent with lymphocytic interstitial pneumonitis (LIP). This was confirmed by a video-assisted thoracoscopic surgical lung biopsy (fig 1). The diagnosis of a pleural-based thymoma was made in the absence of a mediastinal mass on initial imaging.

The thymoma was treated with six cycles of cisplatin and etoposide, with prednisone for the LIP. Follow-up imaging 8 months later showed significant improvement in both the pleural thymoma and LIP.

\section{Pleural thymoma}

Thymomas are epithelial-type neoplasms that typically occur in the anterosuperior mediastinum. Up to $4 \%$ of thymomas originate from ectopic thymic tissue. ${ }^{12}$ Diagnosis of a pleuralbased thymoma is difficult, with the differential diagnosis including lymphoma, mesothelioma, sarcoma and other metastases or spread from a primary pulmonary malignancy.

The course of pleural thymoma is usually indolent with nonspecific symptoms. Imaging can demonstrate a unifocal mass, multifocal masses, diffuse pleural thickening or pleural effusions. Primary pleural thymoma does not have the mediastinal involvement usually seen in lymphoma. Histological examination is required for the diagnosis and has recently been reviewed. ${ }^{2}$ Briefly, thymomas consist of thymic epithelial cells incompletely surrounded by fibrous septae with infiltrating polyclonal lymphocytes. Immunohistochemistry can distinguish thymomas from other malignancies. Cytokeratin stains cells derived from an epithelial lineage, including thymoma and mesothelioma. Thymomas typically stain positive for cytokeratin 5/6, p63, CD99, CDla and TdT. ${ }^{2}$

Our patient had a bilateral pulmonary infiltrate consistent with LIP. While thymomas often have a polyclonal lymphocytic infiltrate, they do not typically cause a diffuse pulmonary infiltrate as seen in this case. To our knowledge this is the first case of a thymoma-associated LIP.

From the question on page 666
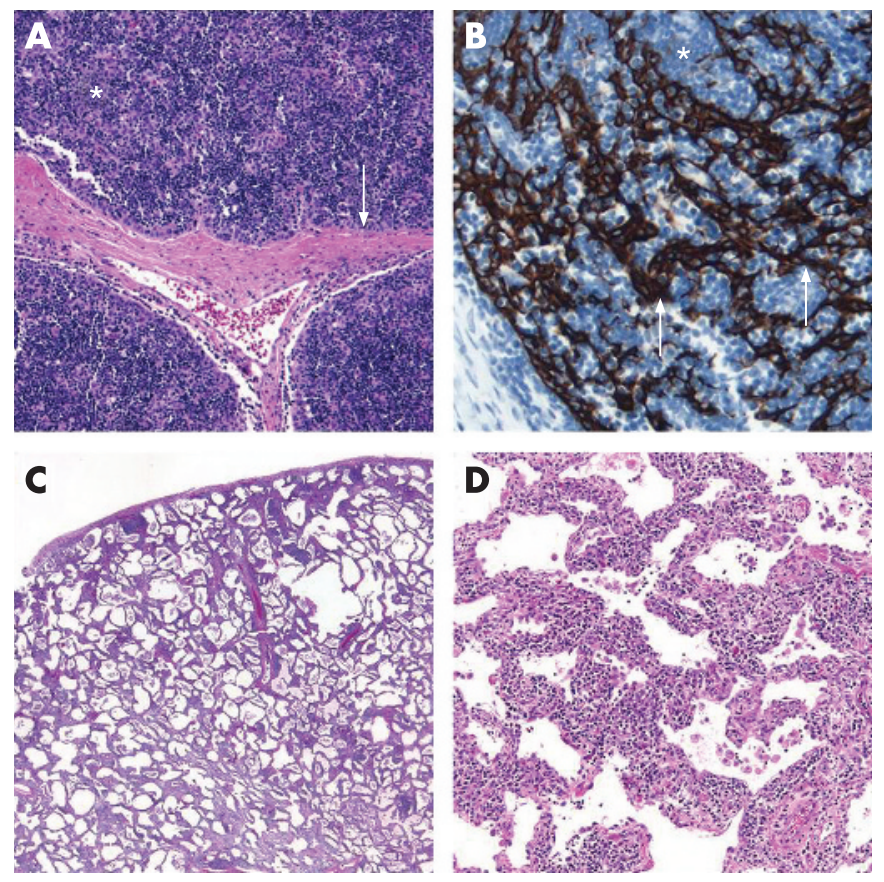

Figure 1 (A) Photomicrograph of thymoma demonstrating the typical features of a lymphoid and epithelial proliferation (*) traversed by hyalinised fibrous septae (arrow). H\&E; 40x original magnification. (B) Medium power photomicrograph of the thymoma in which pankeratin immunohistochemistry (dark stain, arrows) highlights the network of neoplastic thymic epithelial cells interspersed within a benign lymphoid stroma (*). $100 \times$ original magnification. (C) Low power scanning photomicrograph of the lung wedge biopsy demonstrating diffuse interstitial infiltration of lymphocytes and plasma cells. H\&E; $12.5 \times$ original magnification. (D) Medium power photomicrograph of lung wedge demonstrating expansion of the alveolar septae by mononuclear inflammatory cells. $110 \times$ original magnification.

\section{References}

1 Minniti S, Valentini M, Pinali L, et al. Thymic masses of the middle mediastinum: report of 2 cases and review of the literature. J Thorac Imaging 2004;19:192-5.

2 Qing G, lonescu DN, Colby TV, et al. A 75-year-old man with an asymptomatic pleural-based mass discovered on routine chest radiographs. Primary pleural thymoma. Arch Pathol Lab Med 2006;130:e62-5. 